of barium $\mathrm{N}$-acetylglucosamine-6-sulphate. Barium $\mathrm{N}$-acetylglucosamine-monosulphate, prepared by the direct sulphation of $\mathrm{N}$-acetylglucosamine, was identical with barium $\mathrm{N}$-acetylglucosamine-6-sulphate prepared by definite synthesis.

Further evidence as to the location of the sulphate group in position 6 of the hexosamine molecule was obtained by examining the behaviour of the compounds in the Elson-Morgan reaction ${ }^{13}$. Both authentic $\mathrm{N}$-acetylglucosamine-6-sulphate and $\mathrm{N}$ acetylglucosamine monosulphate gave 100 per cent colour production in this test using $\mathrm{N}$-acetylglucosamine as standard. It has been shown that $\mathrm{N}$-acetylhexosamines substituted in position 6 behave normally in the Elson-Morgan reaction whereas substitution in position 3 results in enhanced colour production. On the other hand, substitution in position 4 causes suppression of colour formation ${ }^{14}$. N-acetyl galactosamine monosulphate, prepared by direct sulphation of $\mathrm{N}$-acetyl galactosamine ${ }^{11}$, also gives 100 per eent colour formation in the Elson-Morgan test ${ }^{13}$, providing preliminary evidence of the location of the sulphate group in position 6 of the molecule.

A more complete account of this work, together with the results of enzyme studies, will be given elsewhere.

I am indebted to the Empire Rheumatism Council for a research fellowship, and to Prof. J. Pryde and Dr. K. S. Dodgson for advice and encouragement during the course of the above work.

Department of Biochemistry,

A. G. LLOYD

University College,

Newport Road,

Cardiff. Oct. 22.

${ }^{1}$ Dodgson, K. S., Lloyd, A. G., and Spencer, B., Biochem., J., 65, 131 (1957). Dodgson, K. S., and Lloyd, A. G., ibid., 68, 532 (1957); 68, 88 (1958).

Trevelyan, W. E., Procter, D. P., and Harrison, J. S., Nature, 174, 444 (1950)

${ }^{3}$ Partridge, s. M., Nature, 164, 479 (1949).

4 Partridge, S. M., Biochem. J., 42, 238 (1948).

'Burma, D. P., Anal. Chem., 25, 549 (1953).

- Putman, E. W., "Methods in Enzymology", 3, 57 (Academic Press, New York, 1957).

${ }^{7}$ Soda, T., Bull. Chem. Soc., Japan, 8, 37 (1933).

${ }^{8}$ Dodgson, K. S., and Spencer, B., "Methods of Biochemical Analysis", 4, 211 (Interscience Publishers, New York, 1957).

- Lardy, H. A., and Fischer, H. O. L., "Biochemical Preparations", 2, 39 (John Wiley and Sons, New York, 1952). ${ }^{10}$ Reynolds, D. D., and Evans, W. L., "Organic Syntheses", 22, 56
(John Wiley and Sons, New York, 1942).

11 Roseman, S., and Cudoweig, J., J. Amer. Chem. Soc., 76, 301 (1954).

12 Anderson, J. M., and Percival, E., J. Chem. Soc., 814 (1956).

${ }^{13}$ Amminoff, D., Morgan, W. T. J., and Watkins, W. M., Biochem. J., 51,379 (1952).

"Jeanloz, R. W., and Tremege, M., Fed. Proc., 15, 282 (1954).

\section{Optical Rotation and Configuration of Poly-L-tyrosine}

IN a recent communication from this laboratory ${ }^{1}$ it was reported that the constant $b_{0}$ in Moffitt's equation ${ }^{2}$ for the optical rotation of a helical polypeptide is positive for solutions of poly-L-tryosine in dimethyl formamide and in pyridine, and for the sodium salt of this polymer in solution and in films. It was implied that in spite of the unusual sign of $b_{0}$. the polymer was in the $\alpha$-helical form, and that the positive value is a consequence of the strong chromophoric group near the $\beta$ carbon atom. We have since made further measurements of the optical rotation of a solution of this polymer in $N$ sodium hydroxide and of films cast from a solution in dimethyl formamide at $60^{\circ} \mathrm{r}$., together with observations of the infra-red spectrum and X-ray diffraction pattern of the films. These studies have led us to the conclusion that it is more probable that in dilute solutions in pyridine, in dimethyl formamide, and in aqueous alkali, poly-Ltyrosine is in the random coil configuration, as is its sodium salt in films.

The optical rotatory dispersion results are difficult to interpret unambiguously, because of the unknown effect of the chromophoric groups in the side-chain. There is no reason for supposing that the $\lambda_{0}$ of the Moffitt equation will be the same as in other polypeptides, that $b_{0}$ will be zero for a random coil arrangement, or indeed that the Moffitt equation will hold at all. However, if one nevertheless takes the usual value of $2120 \mathrm{~A}$. for $\lambda_{0}$ and makes a Moffitt plot, one obtains values of $b_{0}$ of about $+300^{\circ}$ for a solution in pyridine, about $+400^{\circ}$ for solutions in dimethyl formamide and in $N$ sodium hydroxide, about $+550^{\circ}$ for films of the sodium salt, and about $-4000^{\circ}$ for films of poly-L-tyrosine cast from dimethyl formamide. It is tempting to suppose that the configuration is different in the last case from that in the others, although the criterion is somewhat arbitrary. The distinction between the films cast from dimethyl formamide and the other systems gradually becomes less clear-cut as $\lambda_{0}$ is increased; however, so far as can be seen from measurements over a rather limited range of wave-length, the Moffitt plot gives the straightest line for $a \lambda_{0}$ of rather less than $2120 \mathrm{~A}$.

Since at $p H \mathbf{H} 14$ the polymer is completely ionized, it would seem unlikely that the solution in aqueous alkali contains a large proportion of the $\alpha$-helical configuration. On the other hand, infra-red spectroscopy and X-ray diffraction provide some evidence that the films cast from dimethyl formamide contain polypeptide in the $\alpha$-helix form. Such films, when rolled, have been found to show marked infra-red dichroism of the kind associated with the $\alpha$-helix. However, this behaviour is not reproducible, some similarly treated films failing to show any dichroism. The X-ray diffraction pattern of $\alpha$-helices of poly-Ltyrosine packed hexagonally would be expected to have a strong ring corresponding to an interplanar spacing of $11.1 \mathrm{~A}$., as may be calculated from the density of the films $(1 \cdot 254 \mathrm{gm}$./c.c.). The X-ray diffraction pattern of these films does indeed have a ring at $11.1 \mathrm{~A}$. ; but it is not particularly strong. Heating the films in vacuo at $130-140^{\circ} \mathrm{C}$. for $2 \mathrm{hr}$. apparently crystallizes the polymer, and the subse. quent $\mathrm{X}$-ray pattern does show a strong $11 \cdot 1 \mathrm{~A}$. reflexion.

The results of these experiments are far from conclusive; but we feel that they strongly suggest that poly-L-tyrosine in each of the three solvents we have used, and its sodium salt in films, are in the random coil configuration, whereas in films cast from dimethyl formamide the polypeptide exists as $\alpha$-helices.

We are indebted to Dr. T. Macdonald for taking the X-ray diffraction photographs in Courtaulds' X-ray Laboratory at Coventry.

\section{A. R. DownIe \\ A. ELLIOTT}

Research Laboratory, Courtaulds Ltd.,

Lower Cookham Road,

Maidenhead. Nov. 11.

'Elliott, A., Hanby, W. E., and Malcolm, B. R., Nature, 180, 1340

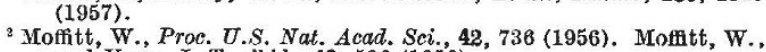
and Yang, J. T., ibid., 42, 596 (1956). 